\title{
Appendiceal Inflammatory Mass. Letter to the Editor
}

\author{
Antonio Jesús González-Sánchez • \\ Jose Manuel Aranda-Narváez • Alberto Titos-García • \\ Custodia Montiel-Casado • Julio Santoyo-Santoyo
}

Received: 19 October 2014 / Accepted: 30 January 2015 / Published online: 18 February 2015

(C) 2015 The Society for Surgery of the Alimentary Tract

\section{Dear Editor}

We carefully read the article by Dr Deelder et al. published in your journal this year regarding the treatment of appendiceal masses, with results that led him to conclude the best treatment for these is direct surgery, based on the high rate of recurrence, the low proportion of patients with suitable surveillance, and the high incidence of underlying malignant tumors. ${ }^{1}$

In this excellent article, Dr Deelder reached this conclusion with a treatment that did not include interval appendectomy as the final step of the conservative treatment given. We agree with the author in that the percentage of recurrence is frankly greater than that published recently, ${ }^{2 \cdot 3}$ as we previously reported. ${ }^{4}$ Due to this, in our appendiceal mass treatment protocol, we systematically include this surgery as the last step of the treatment, which is offered to be carried out between weeks 6 and 8 from the start of the clinical condition (having first carried out a colonoscopy when patients are over 45 years of age). Although the morbidity published with the interval appendectomy in these circumstances ranges from 12 to $23 \%,{ }^{3}$ in our experience, far from it being an aggressive form of surgery, it is in fact a safe procedure. A significant reduction in complications (7 vs. $33 \%$, $p=0.01)$ and, more specifically, the rate of surgical site infection ( 0 vs. $29 \%, p=0.00$ ) was obtained when comparing our series of 27 cases of inflammatory masses treated with this protocol from January 1997 to February 2013 with a control group of patients operated on directly from our historic series (1:1 matching and subsequent random allocation). Furthermore, no greater resection was necessary, with the advantage that, when

\footnotetext{
A. J. González-Sánchez $(\bowtie) \cdot J$. M. Aranda-Narváez •

A. Titos-García $\cdot$ C. Montiel-Casado $\cdot$ J. Santoyo-Santoyo

Hospital Regional de Málaga, Málaga, Spain

e-mail: antoniojgs@yahoo.es
}

carrying out the interval appendectomy, we avoided leaving an inadvertent tumor in the inflamed appendix. And all by means of a procedure that we were able to perform by laparoscopy in $74 \%$ of the cases, compared with $22 \%$ in the control group $(p<0,00)$, always in less than 60 min of surgery time. ${ }^{5}$ In this way, we also had control over recurrence and over the potential hidden tumor pathology.

For all the above, our position, unlike that of Dr Deelder et al., leans more toward initial conservative treatment of appendiceal inflammatory masses with laparoscopic interval appendectomy after 6-8 weeks.

\section{References}

1. Deelder JD, Richir MC, Schoorl T, Schreurs WH. How to treat an appendiceal inflammatory mass: operatively or nonoperatively? J Gastrointest Surg. 2014 Apr;18(4):641-5. PubMed PMID: 24493295.

2. Simillis C, Symeonides P, Shorthouse AJ, Tekkis PP. A meta-analysis comparing conservative treatment versus acute appendectomy for complicated appendicitis (abscess or phlegmon). Surgery. 2010 Jun;147(6):818-29. PubMed PMID: 20149402.

3. Quartey B. Interval appendectomy in adults: A necessary evil? Journal of emergencies, trauma, and shock. 2012 Jul;5(3):213-6. PubMed PMID: 22988397. Pubmed Central PMCID: 3440885.

4. Aranda-Narvaez JM, Gonzalez-Sanchez AJ, Marin-Camero N, Montiel-Casado C, Lopez-Ruiz P, Sanchez-Perez B, et al. Conservative approach versus urgent appendectomy in surgical management of acute appendicitis with abscess or phlegmon. Revista espanola de enfermedades digestivas : organo oficial de la Sociedad Espanola de Patologia Digestiva. 2010 Nov;102(11):648-52. PubMed PMID: 21142385.

5. Aranda Narvaez JGA, B. González Sánchez, AJ. Fernández Burgos, I. Marín Camero, N. Montiel Casado, C. Blanco Elena, JA, Prieto-Puga Arjona, T. Santoyo Santoyo, J. Tratamiento conservador y apendicectomía diferida frente a tratamiento quirúrgico urgente en el manejo de la apendicitis aguda evolucionada. Cirugia espanola. 2013;91(Espec Congr 2):210. 